\title{
UN NUEVO VERISMO: \\ APUNTES SOBRE LA ULTIMA NOVELA MEXICANA
}

POR

NORMA KLAHN

Columbia University

Los periodistas (1978), de Vicente Leñero, constituyc, entre otras cosas, un cjemplo claro de la novelística reciente que evidencia cl cambio formal y por ende idcológico occurrido en la narrativa mexicana a partir de los acontccimientos de Tlatclolco cuando cl gobierno reprimió brutalmente una manifestación estudiantil. Si novelas como Pedro Páramo, El luto humano, Oficio de tinieblas, Recuerdos del Porvenir, Cambio de piel y Terra Nostra recurren al mito y se instalan en un ticmpo cíclico sin salida posible, la novelística despućs del $68 \mathrm{se}$ interesa por experiencias vividas, rompe el ticmpo cíclico al buscar en la historia su matcrial y nos ofrece dentro del mundo novelesco un movimicnto lineal. Ese movimicnto aunque inicia un proceso de descomposición del statu quo liberando a la cscritura del pensamiento mítico y desmitificando la búsqueda de orígenes y de una identidad esencial'.

Esta manifestación no es exclusiva de México. La atmósfera de descontento político y social y las insurrecciones esporádicas de los años sesenta en Latinoamérica inician un nuevo periodo de producción y crítica literaria que al recuperar para el texto un sentido de historia y lugar, cuestiona los textos ya canónicos de las generaciones anteriores marcados por una estructura mitopoética vinculada a la poética surrcalista.

Para fines de los años setenta y principios de los ochenta, críticos como Angel Rama, David William Foster, Carlos Rincón, Julio Ortega y el escritor José Luis González, entre otros, hablan de la existencia de una nueva literatura dentro de la

\footnotetext{
1 Véase mi artículo "Vicente Leñero: De los albañiles a los periodistas, de la ficción a la verificción", A Symposium: Requiem for the "Boom" Premature? eds. Rose Minc and Marilyn Frankenthaler (Montclair, New Jersey: Montclair State College, 1980), pp. 162 173.
} 
cual surge una novelística que privilegia el referente ${ }^{2}$. Esta novelística incorpora cl referente, ya de manera documental, como en las novelas testimonio Biografía de un cimarrón de Miguel Barnet, y llasta no verte Jesús mío, de Elena Poniatowska, ya de manera imaginativa, como en De perfil, de José Agustín, El gran solitario de palacio, de René Avilés Fabila, y Morirás lejos, de Josć Emilio Pacheco.

Estos cscritores forman una gencración de novclistas nacidos entre, aproximadamente 1935 y $1950^{3}$. Al asumir la validez de la consabida afirmación de Tzvetan Todorov de que toda obra es parte de un universo poblado de obras, cl esquema generacional me sirve no como método rígido de análisis reduccionista, sino para darle orden a un matcrial enorme. Se trata de establecer cierta periodización que sin obviar el texto individual considere los vínculos que cxisten entre los distintos textos de una época, sus diferencias y semejanzas con textos anteriores, y la significación de esos tex tos como productos de una cultura y de una época particular.

Durante esta época los escritores jóvenes mexicanos se unen a la búsqueda que cn otros países estaban llevando a cabo grupos afines que cucstionan las estructuras vigentes, la supucsta moral burguesa, las institucioncs que privilegian a cicrtos sectores acomodados de la socicdad y las caducas formas de pensar represivas autoritarias, sexistas y racistas. Los movimientos de derechos civiles en Estados Unidos, la música, el cine y la literatura fucron fundamentales. El novelista René Avilés Fábila documenta esa influencia como significativa de apertura: "El nacionalismo que venía fomentando el gobierno desde la revolución se fatiga y se convierte en demagogia oficial ...." Su generación, continúa, busca enriquecer su visión del mundo con la presencia de los Estados Unidos como las generaciones anteriores lo hicieron mirando hacia Europa. Pregunta: " $¿$ Pero cstamos realmente ante un simple caso de colonialismo cultural? No lo creo. Es algo más complejo.

2 Angel Rama, "Rodolfo Walsh: el conflicto de culturas en Argentina", Escritura 2(1976). David William Foster, "Latin American Documentary Narrative", PMLA 99(1984), pp. 41 55. Carlos Rincón, "El cambio actual de la noción de la literatura", Eco 196 (1978), pp. 385421. Julio Ortega, "La literatura latinoamericana ante la década del 80", II ueso IIúmero 2 (1979), pp. 91-96. Arcadio Díaz Quiñones Conversación con José Luis González (Argenlina: Ediciones Huracán, 1976).

${ }^{3}$ Seguimos pautas cstablecidas por Cedomil Goic, /listoria de la novela hispanoamericana (Chile: Ediciones Universitarias, 1972) y Jaime Giordano, La edad de la náusea: Sobre narrativa hispanoamericana contemporánea (Santiago, Chile: Instituto Profesional del Pacífico, 1985). 
Toda esła gencración se agota después de muchos años de nacionalismo recalcitrante y busca expresiones más cosmopolitas"4.

Esta indicación es significativa y nos ayuda a comprobar la hipótcsis de que con esta generación se inicia un nuevo "verismo" en literatura hispanoamericana. La estética realista que permea, en su mayor parte, la novela de los escritores cstadounidenses desde principios de siglo y de la cual se nutre esta gencración (Hemingway, Fitzgcrald, Salinger, Mailer, Updike, Styron, Capote, Heller) refuerza la voluntad de verdad que busca expresión en las obras de la joven generación mexicana. Opcra una recstructuración que integra en un nuevo sistema cl conjunto del extra texto. Se entiende, como dice Christian Metz, que cl contenido se decide en relación, sobre todo, a las obras anteriores del mismo arte, no directamente de la obscrvación de la vida real, ni directamente por la exploración de la imaginación ${ }^{5}$. Recordemos, además, que lo verosímil se define cn relación a la cultura y adquicre validez según cl país y la ćpoca en que se inscriben. Una escena de amor como se presenta en María, de Jorge Isaacs scría inverosímil en Aura, de Carlos Fuentes o en Tantadel, de René Avilés Fabila.

Estos escritores, asimilados los logros de la vanguardia, reanudan los lazos con la tradición realista. Lejos estamos, sin cmbargo, de la novela que se consideraba laboratorio experimental donde las ideas del decerminismo y la herencia motivaban la conducta del hombre. Lejos de las pretensiones cientificistas que hacían posible a un narrador omnisciente que se instalaba por sobre sus personajes y emilía juicios valorativos fingiendo imparcialidad. Este regreso que privilegia el referente se establece no dentro de la perspectiva racionalista decimonónica, sino dentro de una perspectiva contemporánca que privilegia la complejidad, la ambigüedad y sospecha de verdades absolutas. Este realismo nuevo es consciente de que toda obra eslá mediatizada por un lenguaje cargado de significación. Los textos están dirigidos a lectores habituados a lecr novela contcmporánca. Si el narrador de la novela realista decimonónica mancjaba distintos recursos para crear un efecto de realidad y enmascarar el proceso ficticio, como cxigía la convención del género de la ćpoca, ahora cl autor de la novela ncorealista deja clara su intención de ficcionalizar.

Sc hacstablecido el año de 1968, en México, comocl momento en que se inicia un periodo intenso de cuestionamiento, ruptura y apertura hacia nuevas formas de

\footnotetext{
${ }^{4}$ René Avilés Fabila, "La influencia norteamericana en la reciente literatura mexicana," El búho suplemento de Excelsior 29, septiembre 1985, p 3.

5 Christian Metz, "El decir y lo dicho en el cine: ¿hacia la decadencia de un cierto verosímil?” Lo verosímil (Buenos Aires: Editorial Tiempo Contemporánco, 1968), pp. 1920 .
} 
pensar la realidad y de transcribirla. Los mexicanos se venían cuestionando la supuesta estabilidad y democracia que el gobierno les aseguraba desde la represión de las huclgas ferrocarrileras que toman lugar a fines de los años cincuenta, y del ascsinato del líder obrero Rubén Jaramillo, en 1964. Durante la época de los sesenta se va creando un malestar de índole social que culminará en Tlatelolco y uracrá cambios fundamentales en la visión de mundo del mexicano. De esa encrucijada, donde convergen las fuerzas socio-históricas con la conciencia estćtica, surge una litcratura transformada y transformadora.

Esta generación desmitificadora, que se inscribe dentro de un "verismo" litcrario, rompe con las tres gencraciones anteriores, representadas por Agustín Yáñez, Juan Rulfo y Carlos Fuentes. Sus obras presentan cierla unicidad de visión, y aún con las innovaciones y originalidad que se manifiesta en cada uno de sus textos, una continuidad. Sus novelas mitopoćticas se conciben dentro de un marco superrealista o mítico realista. Esta generación mitificadora, a su vez, había roto con la generación que le precedia, cuya poética suscrita dentro de un realismo racionalista, defendía el concepto de novela como reflejo. En su búsqueda por definir al mexicano, prcocupación que se hace más crítica al adquirir distancia la irrupción de la Revolución Mexicana, autores como Yáñez, Revucltas, Rulfo y Fuentes claboran textos de búsquedas dentro de una estructura que por razones culturales, históricas y litcrarias privilegian el mito.

Hay que notar que a la vez que México, con la Revolución, cobra conciencia de sí mismo como país mestizo, aparecen los movimientos de vanguardia como $\mathrm{el}$ surrcalismo y cl cxpresionismo, cuya estética no sólo permite sino anima la incorporación del cspacio mágico-mítico indigena a la litcratura. El surrealismo privilegia desde un discurso irracional cspacios ignorados o censurados del ser humano y su inconsciente. Como manifestación ética se propuso subvertir los supuestos lógico-racionalistas del positivismo. Sus estrategias en cl campo artístico buscaban desplazar las convenciones del realismo burgués y su visión del mundo. Sus seguidores privilegiaban lo irracional, cl inconsciente, los sucños y la imaginación, espacios donde no operan las relaciones lógicas, temporales y espaciales, en un afán de descubrir la verdadera esencia de la realidad y del hombre. La búsqueda de otras realidades subyacentes tuvo grandes repercusiones en México al coincidir con el momento en que cl mexicano empezaba a definirse mediante un autocuestionamicnto hipercrítico. La traducción de textos aztecas, y la prolifcración de trabajos antropológicos y ctnográficos animaron una literatura que se concentra en desenmascarar al México auténtico desde una poćtica que como dice Lco Pollman pareccría que ic pertenece. Esta estética surrealista impulsará algunas de las mejores novelas mexicanas en lo que va del siglo, entre 
cllas, El luto humano, Pedro Páramo, Oficio de tinieblas, Recuerdos del Provenir, La muerte de Artemio Cruz, Farabeuf.

La tendencia anti-racionalista que anima novelas como El luto humano o Aura culmina en México (por los mismos años que se inicia la nueva poćtica) con las novelas de Salvador Elizondo Farabeuf (1965), y El hipogeo secreto (1968), novelas que se destacan por su estructura circular y anti-referencial. Elizondo confirma su posición en una entrevista cuando dice: "Todo lo que está en una novela, para mí, es una mentira. No debe admitir una correspondencia". Si los autores del neo-realismo cuentan con una audiencia, Elizondo insiste en la novela como acto anti-comunicativo. En Farabeuf se cmprende un viajc hacia lo profundo cn búsqueda de la unidad perdida, en búsqueda de un tiempo sagrado donde se reconcilian los contrarios, lo femenino y lo masculino, la carne y cl espíritu, lo impuro y lo sagrado. Se clabora un tiempo cíclico, la crónica de un instante, cuyo punto de partida es cl punto de llegada. En csta novela la anti-linealidad, lo antianecdólico y anti-referencial adquicren su máxima expresión y con clla se cicrra un capitulo de la historia de la novela mexicana.

La gencración representante de un nucvo "verismo" en México incluye en su ctapa inicial a José Agustín (1944), Renć Avilés Fabila (1940), Gustavo Sainz (1940) y José Emilio Pacheco (1939). Sus obras Gazapo (1965), De perfil (1966), Los juegos (1967) y Morirás lejos (1967) son las primcras manifestaciones de csta ruptura? ${ }^{7}$. Dentro de esa misma línca y en pleno proceso de claboración y desarrollo se encuentran las obras de los que son figuras de transición. Elena Poniatowska (1933), Vicente Leñero (1933) y Fernando del Paso (1935), y los que les siguen como, cntre otros, Juan Tovar (1941), Hugo Hiriart (1942), Jorge Aguilar Mora (1946), Luis González de Alba (194?), Héctor Manjarrez (1944), Hımberto

"Juan Bruce-Novoa, "Entrevista con Salvador Elizondo", La palabra y el hombre 16, pp. 51-58.

${ }^{7}$ Otros textos que tratan la literatura mexicana después del 68: John Brushwood, La novela mexicana 1962-1982 (México: Grijalbo, 1984). Jorge Ruffinelli, "Notas sobre la novela en México, 1975-1980”, Cuadernos de Marcha (julio-agosto 1981), pp. 47-59. José Joaquín Blanco "Aguafuertes de la narrativa mexicana, 1950-1980", Nexos (agosto 1981), pp. 23-39. Luis Lcal, "Tlatclolco, Tlatclolco", Denver Quarterly (Spring, 1979), pp. 3-13. Jean Franco, "The Critique of the Pyramid and Mexican Narrative after 1968", A Symposium: Latin American Fiction Today ed. Rose Minc (Maryland, Hispamérica and New Jersey: Montclair State College, 1980), pp. 59-59. Carlos Montemayor, "Condiciones de la nucva literatura mexicana”, Prólogo a Narrativa Iispanoamericana, 1816-1981 (La generación de 1939 en adelante en México) ed. Angel Flores (Mẹ́xico: Siglo XXI, 1985), pp. 11-16. 
Guzmán (1949), Héctor Aguilar Camín (1946), Armando Ramírcz (194?), Eugenio Aguirre (1944), Joaquín Armando Chacón (1944), Silvia Molina (1946), Carlos Montemayor (1947), Martha Robles (1948), Daniel Leyva (1949), Guillermo Samperio (1948), Angeles Mastreta (1949), Ignacio Solares (1945), María Luisa Puga (1944), Luis Arturo Ramos (1947), y Marco Antonio Campos (1949). Por su producción ya considerable incluyo a José Joaquín Blanco (1951), Luis Zapata (1951) y Agustín Ramos (1952), y tambićn a Margo Glantz (1930) y a Jcsís Gardea (1939), quicnes empiczan a publicar en la década de los ochenta.

Los jóvenes escritores Agustín, Avilés Fabila y Sáinz desconfían de toda autoridad, de las instituciones, de la llamada identidad nacional y de los discursos que las sustentan. Irreverentes, iconoclastas e irónicos se imponen la tarea de desmitifacación y desenmascaramiento. El famoso artículo de 1970 "Happy Recncarnation to you" de Agustín, sobre Cumpleaños, de Fuentes, confirma cl distanciamiento que los jóvenes toman con respecto a sus predecesores ${ }^{8}$. Sus afinidades radican, no con el pensamiento y la visión de Octavio Paz (1914), sino con cl de Carlos Monsiváis (1938).

El genero ensayístico de Monsiváis adquicre la forma necesaria para responder artísticamente y con validez a una época de rápida modernización (Días de guardar [1970]). Capta lo multifacético de la socicdad por medio de una cscritura que parodia y se nutre a la vez de la cultura y los medios de comunicación de masas. Monsiváis aprendió de Salvador Novo que "el español no es nada más cl idioma que los académicos han registrado a su nombre, sino algo vivo, útil," y tambićn "que el sentido de humor no difamaba la esencia nacional". Como Agustín y Sainz introduce lo lúdico y lo humorístico subrayando de manera implícita la solemnidad anti-crítica y conformista de los discursos anteriores; como Avilés Fabila introduce la crítica sarcástica que, sin concesiones, acusa una sociedad, ya no dentro del ámbito del inconsciente colectivo, sino del consciente histórico que posibilita la apertura.

La cscritura de esta generación de novelistas parte de una rcalidad concreta. Las novelas se sitúan en realidades verilicables y sus personajes pertenecen a la vida diaria. No cstamos en Comala sino en la Colonia Roma, en Tepito, en Parral. Aun en las novelas de Jesús Gardea el nombre de Placcres es inmediatamente ubicable. No se esconde su referencialidad, sabemos que es Ciudad Delicias, Chihuahua. Las ćpocas en que los textos toman lugar son explícitos y en muchos

\footnotetext{
${ }^{8}$ José A gustín, "Happy Recncarnation to you", Vida Literaria (marzo 1970), pp. 12-13.

' Carlos Monsiváis, Nuevos escritores mexicanos del siglo XX presentados por símismos (México: Empresas Editoriales, 1966), pp. 49-50.
} 
casos son partes integrales de la trama. Pensamos en Las batallas en el desierto, de José Emilio Pacheco, que toma lugar durante la época de Migucl Alemán, y en Arráncame la vida, de Angeles Mastreta, que recrea la vida de la política mexicana de los años treinta y cuarenta.

Los personajes simbólicos como Natividad, Juan Preciado, Artemio Cruz, Ixca Cienfucgos son recmplazados por protagonistas tomados de la vida diaria: adolescentes, burócratas, políticos, homosexualcs, campesinos, mincros, todos dentro de un espacio ubicable. Esta nueva composición formal imposibilita la interpretación que privilegia búsquedas de origen, recupcración del edén perdido, y diluvios simbólicos. Pasamos de la búsqueda colectiva de orígenes a la búsqueda de lo particular, del mexicano individual, de la patria a la matria.

El vínculo con realidades concretas necesariamente impone un lenguaje nucvo que las registra: el habla del adolescente, del minero del norte, y, hasta del escritor consciente de su obra. Se anuncia un neo-regionalismo también dentro de la escena urbana, que se concentra en lo local, lo particular. La ciudad de México, representada por Fuentes en La región más transparente, coherente en su diversidad, se compartamentaliza ${ }^{10}$.

Durante los años sesenta, y particularmente despućs de los acontecimientos del ' 68 , los cscritores reconocen la diversidad cultural que compone el país. Para cllos la búsqueda de una auténtica mexicanidad se convirtió en un inútil concepto metafísico y parroquial. Se dan cuenta de que al crear estercotipos nacionales se verían obligados a abandonar la complejidad que se les imponía en su labor crítica.

Despućs del ' 71, y en un intento de restaurar su credibilidad, el gobicrno, en una maniobra política muestra una apertura en cuestiones de pensamiento y crítica. Además, promovió actividades culturales, talleres, premios y publicaciones. La proliferación de revistas y el establecimiento de nuevas casas editoriales que publicaban a los jóvenes crearon el espacio que fomentó una intensa actividad literaria. Surgen escritores cuya heterogencidad sirve para encauzar la novela en múltiples direcciones. De allí surgen novelas que renuevan el género temática y estilísticamente. Si todas privilegian la referencialidad, existen las que lo hacen de mancra más transparente, novelas en las que se problematiza la relación entre ficción y realidad. (Se entiende por ficción, no mentira en oposición a verdad, sino invención-la invención que es propia del ordenamiento artístico y que necesariamente conlleva toda obra de creación y re-creación). Si la ficción de lo imaginado crea scres, objetos o acontecimicntos desde el espacio de la imaginación, la ficción

${ }^{10}$ Véase John Brushwood, "Sobre el referente y la transformación narrativa en las novelas de Carlos Fuentes y Gustavo Sáinz, Revista Iberoamericana, vol. 47, 116-117, pp. 49-54. 
de lo verificable re-crea seres, objetos y acontecimientos tomados de la reälidad cmpírica. De manera general pensamos en la novela testimonio, la biografía o autobiografía novelada, el roman a clef, cl roman a these, la novela política satírica. Pensamos cn Los dias y los años, de Luis González de Alba, Ilasta no verte Jesús mío, de Elcna Poniatowska, El gran solitario de palacio, de René Avilés Fabila y Las genealogias, de Margo Glant.

No es sorprendente que si la novela privilegia al referente no haya una recuperación de la novela histórica; ésta, sin embargo, asume distintas estructuras y visión de mundo. Existe un afán de documentación y conocimiento para retomar la tarea de comprender el presente en términos históricos y no mílicos. Esto se ve como constante en muchas de las novelas que buscan recuperar y reconstruir un pasado concreto. En Morirás lejos, por cjemplo, Jaimc Giordano obscrva que la superposición de fases históricas se plantea como una documentación de posibilidades. Nos encontramos con un narrador conjeturante pero conjeturante de verdad. En su estudio sobre esta novela y esta generación, el crítico chileno dice: "El narrador de Morirás lejos no enticnde la historia como un destino, sino como sucesión continua de experiencias, situaciones, conflictos, probabilidades"11. No se trata de inventar el pasado sino de reconstruirlo. Si Los pasos de López, de Jorge Ibargüengoitia, o Terra Nostra, de Carlos Fuentes, que pertenecen a la generación anterior, parodia o inventa oura historia en búsqueda de un origen, novelas como Gonzalo Guerrero, de Eugenio Aguirre, Ascensión Tun, de Silvia Molina, y Juan Cabezón de Castilla de Homero Aridjis se presentan como reconstrucciones del pasado. No se trata de una nostalgia obvia. El personaje en Las batallas en el desierto dice al final: "No hay memoria del México de aquellos años. Y a nadie le importa: de ese horror quien puede tener nostalgia":2. La afirmación de este narrador maduro se da como paradoja y crítica: la nostalgia es el móvil que revive el pasado como primer paso a su desmitificación.

Otro fenómeno de esta nueva generación es la recuperación de la provincia, recupcración que se empieza a notar a fines de los setenta y principios de los ochenta. Esta búsqueda de nucvos cspacios literarios, que no sca cl de la capital, es significativo de un intento de descentralización estético que cuestiona implícitamente el centralismo cultural y sociopolítico imperante. De este desco de reubicación, por cjemplo, se forma cl grupo de escritores chihuahuenses. Estos escritores (Carlos Montemayor, Jesús Gardea, Ignacio Solares, Joaquin Armando

11 Jaime Giordano, "Transformaciones narrativas actuales. Morirás Lejos de José Emilio Pacheco", Cuadernos Americanos 258.1 (febrero 1985), pp. 133-140.

12 José Emilio Pacheco, Las batallas en el desierto (México: Era, 1981), pp. 67-68. 
Chacón, Víctor Hugo Rascón Banda, Vicente Anaya) diversos entre sí, con un proyecto en común, han contribuido a establecer un diálogo entre jóvenes escritores chihuahuenses y la cultura de la capital.

Gardea, Montemayor y Rascón Banda ubican sus obras en el norte. En su ncoregionalismo no existe una dicotomía entre ciudad y campo. Destacan, como el resto de esta generación, el espacio de la violencia que, en este caso, configuran ambos. Buscan re-cscribir cl campo, desplazamiento que insiste en recordarnos que lo mexicano no se reduce a la capital, que hay otras historias y otras experiencias que merecen ser narradas.

El afán de narrar lo no narrado se destaca en esta gencración. La novela gay, la novela de los barrios obreros y toda la producción de las mujeres es significativo del intento de darle voz y autoridad a experiencias inéditas. Se trata de convertir, en terminología de Christian Metz, los posibles de lo real en posibles del discurso ${ }^{13}$. Dice Margo Glantz "Yo he llegado a escribir por lo que considero una necesidad femenina: entender lo que soy, lo que significa ser mujer" 14 . En la novela de Danicl Lcyva, Una piñata llena de memoria dice un personaje, "Es inclinación natural de todos los que tenemos la suerte de liegar a vicjos, el querer formar una idea en la mente de los jóvenes, de lo que fue nuestra propia vida, a veces, por medio de oportunos consejos, en otras, a través de relatos amenos, como trato de hacerlo, consultando $\mathrm{en} \mathrm{el}$ archivo de mis recuerdos, pues de no sacarlos a la luz, su destino scria permanecer mudos para siempre, en el cementcrio del olvido"15. La experiencia individual sirve para conoccrse y darse a conocer en un mundo donde sólo es posible cl conocimiento parcial.

Muchas novelas responden al diario vivir e insisten en que lo cotidiano es narrable. Se distancian de las novelas de Juan García Ponce donde lo cotidiano sirve para alcanzar un conocimiento metafísico, de esencias cternas. En las novelas de la última generación se recrea la complejidad y la problemática de la vida diaria mås como condición histórica que ontológica. Las novelas buscan darle forma a experiencias y sensaciones nuevas, en un intento de compreensión y resolución vital. El tcma del ' 68 queda integrado a muchas de estas novclas cuyo marco histórico es la actualidad urbana. Resultan de interés especial aquellas que tratan las relaciones amorosas como respucsta a los nucvos roles que ha asumido la mujer.

\footnotetext{
13 Met7., 24-26.

14 "Fragmentos y aquelarres", Entrevista a Margo Glantz por Rosario Ferré, Reintegro 1.3 (1981), p. 21.

${ }^{15}$ David Leyva, Una piñata llena de memoria (México: Joaquín Mortiz, 1984), pp. 14-15.
} 
Tantadel (1975), de René Avilés Fabila, es un buen ejemplo de este tipo de novela donde queda clara la ruptura estética e ideológica que establece esta gencración con la anterior. Si Aura (1962) se establece dentro de las coordenadas de lo irreal, de un tiempo sin ticmpo, Tantadel se ubica dentro de un espacio concreto y en una época determinada. El narrador conjeturante elabora una serie de posibilidades que, reales o fingidas, son posibilidades verosímiles, la estructura de la novela es lincal. Aura, seguirá reaparcciendo en una sucrte de cterno retorno; Tantadel, aunque termina con el comienzo, no establece una estructura cíclica sino un punto de partida hacia lo incierto, hacia lo todavia no escrito.

Tantadel recrea de mancra muy lograda la situación de la parcja contemporánca. Si Aura trata cl tema del amor, la mucrte, el ticmpo como categorías cternas, Tantadel cuestiona las relaciones actuales, la infidelidad, cl divorcio, cl matrimonio, la familla y la procreación en un momento de cambios fundamentales que han alterado las relaciones amorosas entre hombres y mujeres. En esta novela cl narrador representa al hombre enfrentado a una situación nucva y concreta. Tantadel es posibilidad real, no tiene las dimensiones místicas y míticas de Aura, aunque también encarna cl misterio y la tentación femenina.

Si cl narrador de Aura va cn busca de su verdadera máscara y la encuentra, el narrador de Tantadel se csconde tras difcrentes máscaras. En su jucgo de creación y destrucción, ćste clabora una red infinita de posibilidades que al final lo atrapa. En cl mundo mágico-mítico de la novela de Fuentes, Aura es ambas, esposa y amante. En el mundo cotidiano de Avilés Fabila, la mujer no logra esa reconciliación. El narrador nunca se arricsga a escoger una de las tantas posibilidades tentadoras para realizarse cmocionalmente. Además, autoritario e inseguro en su rol masculino, le nicga a la mujer una procrcación biológica y estética. En un movimiento de usurpación simbólica busca procrear desde su imaginación y su escritura. No es casual que con Tantadel dé a luz un libro. Invierte los roles, es fecundado por Tantadel, principio femenino, musa gencradora necesaria para su parto procreador. El tílulo del libro no alude a la protagonista sino al libro que clla de manera pasiva le ayuda a engendrar. La resolución en el espacio de la irrealidad que propone Aura, se hace imposible en el espacio real de Tantadel.

Sabemos que las obras literarias, aunque rompan con poćticas anteriores, constituyen sicmpre una continuidad; cl vínculo de Tantadel con María y Aura cs obvio: las novclas no tratan sobre esas protagonistas sino sobre el narrador que las crea, las idcaliza y las destruye.

La cstćtica superrealista y nco-realista son, finalmente, mancras de ordenar un texto. Aura y Tantadel, dos novelas cortas de excelente factura, logran, desde distintas poćticas, lo que toda obra genuina busca, transformar a travćs de la 
experiencia literaria al lector y la literatura, cuestionar radicalmente la época y la socicdad a la cual se integran, transgredir de manera agresiva los hábitos de lecr, y por ende de pensar del lector, retar su sentido del mundo. La obra genuina se sitúa cn una estética sin obviar la otra: el pensamiento lógico es tan necesario para claborar mundos "irreales" como la imaginación creativa para construir mundos "rcalcs." 
